\title{
Synergism between ipratropium and theophylline in asthma
}

\author{
HARVEY KREISMAN, HAROLD FRANK, NORMAN WOLKOVE, AND MICHAEL GENT \\ From the Sir Mortimer B Davis Jewish General Hospital, and McGill University, School of Medicine, \\ Montreal, Quebec, and McMaster University, Faculty of Health Sciences, Hamilton, Ontario, Canada
}

ABSTRACT Ipratropium bromide is a bronchodilator whose effect has been compared with beta agonists but not with theophylline. Twelve asthmatics were given four two-week courses of the different combinations of ipratropium ( $40 \mu \mathrm{g}$ in two puffs), theophylline capsules, and their corresponding placebos in a random, double-blind fashion. There was a significant increase in $\mathrm{FEV}_{1}$ and MMFR 60 minutes after theophylline was administered $(\mathrm{p}<0.05)$ when measured after one and two weeks of therapy. $\mathrm{FEV}_{1}$ and MMFR were significantly increased $(\mathrm{p}<0.05) 30$ and 60 minutes after ipratropium inhalation and this increase was significantly greater when the patient had also been taking theophylline compared with placebo capsules $(p<0.05)$. There was no toxicity associated with this combination. The synergism demonstrated may be related to the time sequence of drug administration, mechanical or cellular factors.

Anticholinergic agents have been employed for centuries for the treatment of bronchial asthma. ${ }^{12}$ A number of studies have shown that atropine compounds are effective bronchodilators in patients with asthma or chronic obstructive lung disease. ${ }^{2-6}$ Their clinical use has been limited, however, by the concern over local (secretion-drying) and systemic (ocular, cardiovascular) toxicity. Ipratropium bromide is an anticholinergic agent that is structurally similar to atropine. ${ }^{2}$ However its use has been free of the undesirable systemic effects of atropine.

The interaction, and relative efficacy of anticholinergic medication and beta sympathetic agonists such as isoprenaline, fenoterol, and salbutamol, have been studied, ${ }^{6-10}$ but similar studies with ipratropium and oral theophylline have not been done. The purpose of the present study was to assess the efficacy of ipratropium and to establish whether there was any synergism with oral theophylline.

\section{Methods}

Individuals participating in this study had asthma as defined by the American Thoracic Society. ${ }^{11}$ All subjects had evidence of reversible airway obstrucAddress for reprint requests: Dr N Wolkove, Jewish General Hospital, 3755 Cote Street, Catherine Road, Montreal, Quebec H3T 1E2, Canada. tion as manifest by either a $20 \%$ or greater increase in forced expiratory volume in one second $\left(\mathrm{FEV}_{1}\right)$ within 30 minutes of inhalation of $200 \mu \mathrm{g}$ of salbutamol, or a day-to-day variation in $\mathrm{FEV}_{1}$ in excess of $15 \%$.

Informed consent was obtained from all subjects, and this study was approved by the hospital ethics committee.

One of 12 subjects currently smoked one to five cigarettes daily, while six were ex-smokers (1025 pack-years, mean $17 \pm 1 \cdot 7$ pack-years), and five had never smoked. No subject had a history of chronic bronchitis, cardiac, renal, or hepatic disease.

For the purpose of this study an optimum theophylline dose for a particular patient was defined as that quantity which produced the highest serum theophylline concentration in the desired therapeutic range $(10-20 \mu \mathrm{g} / \mathrm{ml})$ one hour after ingestion, without producing side-effects. In a preliminary study each subject's optimum theophylline dose was determined after open administration of different doses of the choline salt of theophylline (oxtriphylline) for three days. Serum theophylline was measured by ultraviolet spectrophotometry. ${ }^{12}$ Thereafter, both theophylline (at previously determined optimum dosage) and placebo oral study agents were identically enclosed within opaque gelatin capsules. Similarly, 
ipratropium ( $40 \mu \mathrm{g}$ in two puffs) or its corresponding placebo were inhaled from indistinguishable metered dose inhalers.

Pre-study pulmonary function tests were obtained in all participants at the time of qualification. Studies were performed using a Collins 14-litre water seal spirometer. Three forced expiratory manoeuvres were performed at one-minute intervals. From each tracing, the vital capacity (VC), $\mathrm{FEV}_{1}$, and the maximum mid-expiratory flow rate (MMFR) were calculated. The pre-study VC, FEV ${ }_{1}$ and MMFR were then determined by obtaining the means of the three determinations. Predicted values were obtained from the data of Bates et al. ${ }^{13}$

Each subject then underwent four different twoweek courses of the four possible combinations of theophylline, ipratropium, and their corresponding placebos, administered four times daily in a random, double-blind fashion. Therefore each subject served as his own control, and the four treatment regimens compared were: theophylline+ ipratropium, referred to as treatment regimen (A), placebo capsule + ipratropium (B), theophylline + placebo inhaler (C), placebo capsule + placebo inhaler (D). A three-day wash-out period was interposed between each of the four treatment periods. During the wash-out phase theophylline was not administered. At all times individuals were permitted to continue beta agonists or corticosteroids or both, but the doses of all maintenance therapy were kept constant.

Pulmonary function testing was done at the same time in the morning immediately before the beginning of each of the four treatment courses (pre-treatment values), and after one and two weeks of therapy. On the latter two occasions, the test capsule only was taken one hour before coming to the laboratory. Subsequently, on arrival in the laboratory, pulmonary function studies were repeated, and the $\mathrm{FEV}_{1}$ and MMFR calculated as described above. These values hereafter referred to as "baseline", therefore actually represent those obtained one hour after oral medication, immediately before aerosol administration. Two puffs of the test aerosol were then administered and the mean $\mathrm{FEV}_{1}$ and MMFR similarly obtained 30 and 60 minutes later. Other medication was omitted for 10 hours, and smoking was prohibited for two hours, before and until termination of the testing.

Blood was drawn for determination of serum theophylline concentration one hour after ingestion of the test capsule.

Each subject kept a diary describing daily respiratory symptoms, benefits, and side-effects of test medications, and need for other bronchodilators. Subjective parameters were recorded in the diary and scored as follows: overall benefit (better $=+1$, same $=0$, worse $=-1$ ), amount of wheezing (less $=+1$, same $=0$, more $=-1$ ), shortness of breath, and chest tightness (each on a scale of $1-10,10$ being best, 1 being worst).

An analysis of variance procedure appropriate to the $2^{2}$ factorial design was used to assess the overall efficacy of ipratropium, the overall efficacy of theophylline, and any synergism between these two treatments. The overall ipratropium effect was assessed by comparing the mean change in FEV (or MMFR) when the patient was on ipratropium (with or without theophylline) with the corresponding change when the patient was on placebo inhaler. The overall theophylline effect was calculated in a similar manner.

If ipratropium and theophylline merely act in an additive fashion the effect of ipratropium would be expected to be the same in the presence of theophylline or placebo capsules. Synergism between these agents was therefore sought by determining whether the effect of ipratropium was significantly greater in the presence of theophylline versus placebo capsules. ${ }^{14}$

\section{Results}

Seven males and five female asthmatic subjects aged 21-54 years (mean $34 \pm 2.4$ yr) completed the study. Three other individuals withdrew from the study before completion, and were excluded from statistical analysis. The three subjects who withdrew from the study did so for the following reasons. One completed the first treatment period (theophylline and placebo aerosol) but claimed the capsules made her "high". Another subject completed one week of theophylline and placebo aerosol, but was too ill to abstain from bronchodilators for the required 10 -hour period before testing. The third subject completed two weeks of placebo capsules, and placebo aerosol but discontinued because of the inconvenience of repeated testing.

The mean optimum theophylline dose $( \pm \mathrm{SE})$ O was $1183 \pm 96 \mathrm{mg}$ daily of the choline salt (range 6 800-2000 mg). Serum theophylline concentration one hour after active capsule ingestion was 13.8 $\pm 0 \cdot 1 \mu \mathrm{g} / \mathrm{ml}$.

The results of pre-study pulmonary function tests are summarised in table 1.

The FEV ${ }_{1}$ and MMFR data, averaged over the 12 individuals for the various study periods are shown in table 2 . The pretreatment values were 
somewhat variable among the four treatment groups, but the observed differences were not statistically significant. The results for week 1 and week 2 , within specific treatment regimens were not significantly different, and it was appropriate and efficient simply to average these values for the two weeks.

Table 1 Pre-study pulmonary function tests (mean $\pm S E$ )

\begin{tabular}{lllll}
\hline Test & $\begin{array}{l}\text { Before } \\
\text { bronchodilator }\end{array}$ & $\%$ Predicted & $\begin{array}{l}\text { After } \\
\text { bronchodilator }\end{array}$ & $\%$ Predicted \\
\hline FEV & $2 \cdot 0( \pm 0 \cdot 2)$ & $65( \pm 5 \cdot 6)$ & $2 \cdot 5( \pm 0 \cdot 2)$ & $81( \pm 6 \cdot 8)$ \\
$(1)$ & $1 \cdot 1( \pm 0 \cdot 1)$ & $29( \pm 3 \cdot 3)$ & $1 \cdot 6( \pm 0 \cdot 2)$ & $43( \pm 4 \cdot 4)$ \\
$\begin{array}{l}\text { MMFR } \\
(1 / s)\end{array}$ & $1 \cdot 5$ & $73( \pm 7 \cdot 1)$ & - \\
$\begin{array}{l}\text { FEV } / \\
\text { VC }(\%)\end{array}$ & $58( \pm 3 \cdot 0)$ & - & & \\
\hline
\end{tabular}

The effect of theophylline, which is a combined benefit of both chronic and acute administration, can be assessed by comparing the "baseline" values with the pre-treatment values. On this basis, there was a significant theophylline effect with a mean increase in $\mathrm{FEV}_{1}$ of $0.33 \pm 0.16$ litres $(\mathrm{p}<0.05)$ and a mean increase in MMFR of $0.23 \pm 0.12$ litres $/ \mathrm{s} \quad(\mathrm{p}<0.05)$. There was no demonstrable effect of chronic administration of ipratropium, similarly assessed by comparing pretreatment to baseline values in regimens in which the active inhaler had been administered.

The overall benefit of acute administration of ipratropium, as calculated by determining the ipratropium effect, was assessed by comparing the mean increases at 30 minutes and 60 minutes after inhalation with the corresponding baseline values. These mean increases are summarised in table 3 . The efficacy of ipratropium is reflected in a relative mean increase in $\mathrm{FEV}_{1}$ of $0.20 \pm 0.05$, and $0 \cdot 19 \pm 0.06$ litres at 30 and 60 minutes respectively $(\mathrm{p}<0.001)$. The corresponding increases in MMFR
Table 3 Mean increases in FEV ${ }_{1}$ and MMFR after weeks 1 and 2

\begin{tabular}{|c|c|c|c|c|}
\hline \multirow[t]{2}{*}{ Treatment regimen } & \multicolumn{2}{|c|}{$F E V_{1}(l)$} & \multicolumn{2}{|c|}{$\operatorname{MMFR}(l / s)$} \\
\hline & $30 \mathrm{~min}$ & $60 \mathrm{~min}$ & $30 \mathrm{~min}$ & $60 \mathrm{~min}$ \\
\hline $\begin{array}{l}\text { Theophylline and } \\
\text { ipratropium (A) }\end{array}$ & 0.29 & 0.40 & 0.31 & 0.45 \\
\hline $\begin{array}{l}\text { Placebo and } \\
\text { ipratropium (B) }\end{array}$ & 0.26 & $0 \cdot 27$ & $0 \cdot 22$ & $0 \cdot 24$ \\
\hline $\begin{array}{l}\text { Theophylline and } \\
\text { placebo (C) }\end{array}$ & 0.02 & 0.07 & 0.04 & $0 \cdot 12$ \\
\hline $\begin{array}{l}\text { Placebo and placebo } \\
\text { (D) }\end{array}$ & $0 \cdot 14$ & 0.22 & $0 \cdot 11$ & $0 \cdot 18$ \\
\hline $\begin{array}{l}\text { Ipratropium effect } \\
\mathbf{A}+\mathbf{B}-\mathbf{C}+\mathbf{D}\end{array}$ & $0 \cdot 20$ & $0 \cdot 19$ & $0 \cdot 19$ & $0 \cdot 20$ \\
\hline $\begin{array}{l}\stackrel{2}{2} \underset{2}{\text { Effect of ipratropium }} \\
\text { in the presence of } \\
\text { theophylline }(A-C)\end{array}$ & $0 \cdot 27$ & $0 \cdot 33$ & $0 \cdot 27$ & 0.33 \\
\hline $\begin{array}{l}\text { Effect of ipratropium } \\
\text { in the presence of } \\
\text { placebo (B-D) }\end{array}$ & $0 \cdot 12$ & 0.05 & $0 \cdot 11$ & 0.06 \\
\hline
\end{tabular}

were $0 \cdot 19 \pm 0 \cdot 05$ and $0 \cdot 20 \pm 0.06$ litres/s at 30 and 60 minutes respectively $(\mathrm{p}<0.001)$.

Further analysis showed that the observed increases in $\mathrm{FEV}_{1}$ and MMFR after ipratropium were consistently greater with the concomitant use of theophylline than they were when the patients were taking placebo capsules. These increases are shown diagramatically in figs 1 and 2 for FEV $_{1}$ and MMFR respectively. The indicated differences in these increases, which represent a measure of the synergism between the two drugs, were statistically significant at 60 minutes; $0.28 \pm$ 0.13 litres for $\mathrm{FEV}_{1}$ and $0.27 \pm 0.11$ litres/s for MMFR ( $p<0.05$ in both cases).

The subjective scores for overall benefit, amount of wheezing, shortness of breath, and chest tightness demonstrated a statistically significant beneficial effect with theophylline $(p<0.05)$ but not with ipratropium. Subjects coughed more when on ipratropium treatment regimens.

Pulse rates did not vary significantly with any of

Table 2 Effect of therapy on FEV $V_{1}$ and MMFR

\begin{tabular}{|c|c|c|c|c|}
\hline & $\begin{array}{l}\text { Theophylline and } \\
\text { ipratropium }(A)\end{array}$ & $\begin{array}{l}\text { Placebo and } \\
\text { ipratropium }(B)\end{array}$ & $\begin{array}{l}\text { Theophylline and } \\
\text { placebo }(C)\end{array}$ & $\begin{array}{l}\text { Placebo and } \\
\text { placebo }(D)\end{array}$ \\
\hline \multicolumn{5}{|l|}{$F E V_{1}(I)$} \\
\hline $\begin{array}{l}\text { Pre-treatment } \\
\text { Mean (weeks } 1+2 \text { ) }\end{array}$ & $1 \cdot 78$ & $1 \cdot 85$ & $2 \cdot 05$ & $2 \cdot 09$ \\
\hline 60 min after capsule* & 1.93 & $1 \cdot 76$ & $2 \cdot 18$ & $1 \cdot 80$ \\
\hline $30 \mathrm{~min}$ after inhaler & $2 \cdot 22$ & 2.02 & $2 \cdot 20$ & $1 \cdot 94$ \\
\hline $\begin{array}{l}60 \text { min after inhaler } \\
M M F R(l / s)\end{array}$ & $2 \cdot 33$ & 2.03 & $2 \cdot 25$ & 2.02 \\
\hline $\begin{array}{l}\text { Pre-treatment } \\
\text { Mean (weeks } 1+2)\end{array}$ & 0.98 & $1 \cdot 01$ & $1 \cdot 15$ & $1 \cdot 20$ \\
\hline 60 min after capsule* & 1.04 & 0.96 & $1 \cdot 29$ & 0.98 \\
\hline 30 min after inhaler & $1 \cdot 35$ & $1 \cdot 18$ & $1 \cdot 33$ & 1.09 \\
\hline $60 \mathrm{~min}$ after inhaler & $1 \cdot 49$ & $1 \cdot 20$ & $1 \cdot 41$ & $1 \cdot 16$ \\
\hline
\end{tabular}

*Baseline values (see text) 


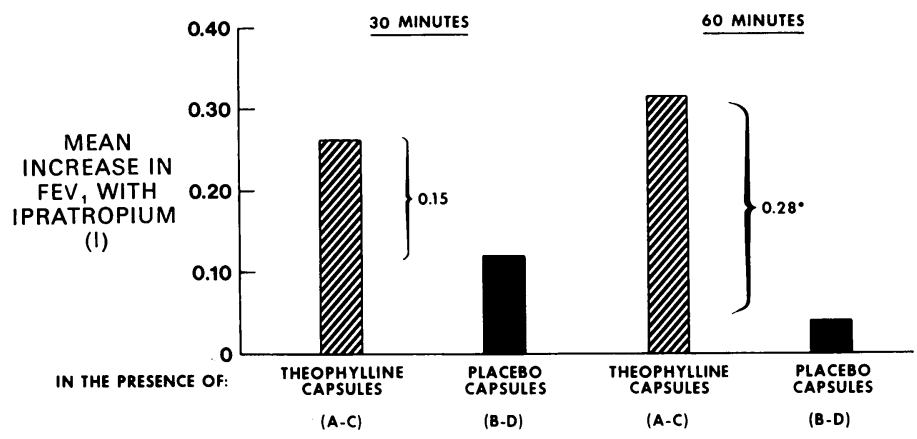

Fig 1 Mean increase in FEV with ipratropium 30 and 60 minutes after inhaler administration. There is a significantly greater effect of ipratropium in the presence of theophylline versus placebo (synergism) 60 minutes after inhaler administration. $(A-C)-(B-D)=$ $0.28(p<0.05)$ see table 3 .

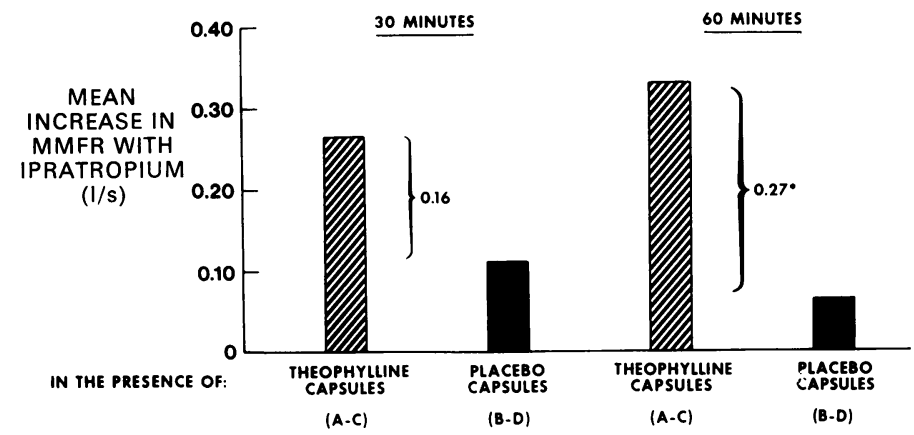

Fig 2 Mean increase in MMFR with ipratropium. As in fig 1, there is evidence for synergism between ipratropium and theophylline 60 minutes after inhaler administration. $(A-C)-$ $(B-D)=0.27(p<0.05)$ see table 3 .

the four treatment regimens. Side-effects were reported equally in all treatment regimens.

\section{Discussion}

The results of this study demonstrate a significant acute bronchodilator response to ipratropium after one and two weeks of regular therapy in subjects with asthma. No tachyphylaxis developed during the two weeks of treatment. There was no chronic objective benefit on baseline pulmonary function after therapy with ipratropium. This result is expected since the duration of its bronchodilator effect is only six hours. Previous studies confirm the efficacy of ipratropium. ${ }^{24515}$ Its bronchodilator effect has been at least as great and of longer duration than isoprenaline in single dose studies. ${ }^{715}$ Comparative studies with salbutamol demonstrate a greater response to ipratropium in subjects with chronic bronchitis ${ }^{4} 8$ but not with asthma. ${ }^{16}$

The vagus nerve is an important modulator of airway function. It is felt that ipratropium, like atropine, acts by a vagolytic action. Our subjects were assessed for historical evidence of the vagal influence on airway obstruction by questioning them about their response to cigarette smoke, dust, air pollutants, upper respiratory tract infection, and cold water. There was a poor correlation between these responses and the efficacy of ipratropium in this study.

The baseline $\mathrm{FEV}_{1}$ and MMFR improved significantly in subjects receiving theophylline. The experimental design used did not enable us to dif- $\frac{x}{\sigma}$ ferentiate the acute from the chronic positive 3 . effect, as the baseline values at one and two weeks $\delta$ were actually one hour after theophylline in- $₹$ gestion. The serum theophylline was already with- 을 in the desired therapeutic range, and therefore it was understandable that no additional benefit occurred 30 or 60 minutes later unless ipratropium was administered.

We have demonstrated synergism between theo- $\mathbb{O}$ phylline and ipratropium 60 minutes after inhala- $\underset{\omega}{N}$ tion of the latter medication (two hours after theophylline ingestion). This indicates that the

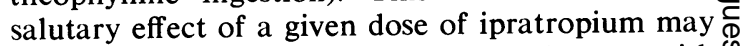
be positively enhanced by previous therapy with $\stackrel{\mathcal{P}}{+}$ theophylline. In North America the latter medi- 70 cation serves as the mainstay of therapy in many cases of asthma and the addition of ipratropium $\stackrel{\Phi}{\Phi}$ is therefore a rational therapeutic approach. The $\mathscr{\mathbb { D }}$ administration of ipratropium was not associated with any toxicity. Since it interacts with theo- 
phylline it may permit more effective bronchodilatation without the need for high and potentially toxic doses of the latter medication.

The physiological basis for the synergism of ipratropium and theophylline remains speculative. Both mechanical and biochemical mechanisms may be operative. Effective administration and absorption of a bronchodilator by metered dose aerosol may be hindered by either the inability to take a deep breath or a shortened period of breath holding after inhalation of the medication. These effects are greater with more severe airway obstruction. The initial bronchodilator effect of theophylline may have enabled subjects to deliver ipratropium more effectively, particularly to distal airways.

On a cellular level, it is known that theophylline inhibits mediator release from mast cells by decreasing destruction of cyclic adenosine monophosphate. Ipratropium prevents mediator release by inhibiting acetylcholine mediated increases in cyclic guanosine monophosphate. ${ }^{17}$ Therefore, the interaction of these two drugs might be explained ultimately on a cellular level by their ability to inhibit mediator release by acting on different biochemical pathways.

We thank Helen Jenne and Marilena Presta for their technical assistance, Anita Itel and Donna Cohen for their help in preparation of the manuscript, and Boehringer Ingelheim (Canada) Ltd for suppling the inhalers.

\section{References}

1 Emirgil C, Dwyer K, Baskette P et al. A new parasympatholytic bronchodilator. A study of its onset of effect after inhalation. Curr Ther Res 1975; 3:215-24.

2 The place of parasympatholytic drugs in the management of chronic obstructive airways disease. Proceedings of an International Symposium. Postgrad Med J 1975; 51 suppl 7.

3 Cavanaugh MJ, Cooper DM. Inhaled atropine sulfate: dose response characteristics. $\mathrm{Am}$ Rev Respir pis 1976; 114:517-24.

4 Poppius H, Salorinne Y. Comparative trial of a new anticholinergic bronchodilator, Sch 1000 , and salbutamol in chronic bronchitis. Br Med J 1973; 4:134-6.

5 Gross NJ. Sch 1000: a new anticholinergic bronchodilator. Am Rev Respir Dis 1975; 112:823-8.

6 Petrie GR, Palmer KNV. Comparison of aerosol ipratropium bromide and salbutamol in chronic bronchitis and asthma. Br Med J 1975; 1:430-2.

7 Yeager H, Weinberg RM, Kaufman LV, Katz S. Asthma: comparative bronchodilator effects of ipratropium bromide and isoproterenol. J Clin Pharmacol 1976; 16:198-204.

8 Douglas NJ, Sudlow MF, Flenley DC. Bronchodilatation with ipratropium bromide in severe chronic bronchitis. Thorax 1977; 32:645.

9 Lightbody I, Ingram C, Legge JS, Johnston RN. Ipratropium bromide, salbutamol, and prednisolone in bronchial asthma and chronic bronchitis. Thorax 1977; 32:645.

10 Minette A, Marcq M, Bruninx M, Spaas B, Hove G Van. Résultats d'une rècherche sur les effets ventilatoires et associés du Sch 1000 en aérosol chez 54 patients atteints de broncho-obstruction reversible. Rev Institut Hyg Mines (Hasselt) 1973; 28:22-38.

11 American Thoracic Society. Definitions and classification of chronic bronchitis, asthma and pulmonary emphysema. Am Rev Respir Dis 1962; 85:762-9.

12 Gupta RC, Lundberg GD. Quantitative determination of theophylline in blood by differential spectrophotometry. Analytical Chemistry 1973; 45:2403-5.

13 Bates DV, Macklem PT, Christie RV. Respiratory function in disease. Second edition. Philadelphia: WB Saunders, 1971:93-6.

14 Steel RGD, Torrie JH. Principles and procedures of statistics. New York: McGraw-Hill, 1960: 194-9.

15 Storms WW, DoPico GA, Reed CE. Aerosol Sch 1000. An anticholinergic bronchodilator. Am Rev Respir Dis 1975; 111:419-22.

16 Lahdensuo A, Viljanen AA, Muittari A. A comparative study concerning a new anticholinergic drug, Sch 1000, salbutamol and placebo in asthma. Scand J Clin Lab Invest 1973; 31 suppl 130:16.

17 Austen KF, Orange RP. Bronchial asthma. The possible role of the chemical mediators of immediate hypersensitivity in the pathogenesis of subacute chronic disease. Am Rev Respir Dis 1975; 112:423-36. 